\title{
Sustainable Concepts of Traditional SanskritTheatre:the Harippad Subrahmanya Swami Temple, Alleppy.
}

\author{
Vinayakan Ashokan, N. Lakshmi Thilagam
}

\begin{abstract}
Traditionally built structures have withstood the onslaught of time and weather conditions for thousands of years due to their dexterity in construction and design. Their unique structures and designs have opened up a new genre of architectural discipline. Over the years, globalization and man's quest for innovative designs and materials have revolutionized the conceptual and architectural practices, which have resulted in the gradual degradation and destruction. The paradigm shift has resulted in losing not only the traditional architectural heritage but also the sustainable practices associated with it. Therefore, it is time we developed new approaches with regard to the design and construction of Koothambalams. Such a step will indeed open up new grounds for technical innovations and critical appraisal of traditional practices and designs. There is a lot more technical knowhow involved in these structures than meets the eye.

The paper is an attempt to explore the traditional architectural practices and sustainable concepts of the Koothambalam of Sree Subramanya temple theatre, Harippad, Alleppy. The Koothambalam not only depicts the tangible realization of age old architectural secrets, but also serves as a meeting place for the community to socialize and experience ancient performing artforms. Within the premise of the temple, there are numerous ancient structures of which Koothambalam is meant for performing cultural and traditional artforms. The proposed research involves an appraisal and listing of the best architectural practices used in the construction of the Koothambalam. Special attention is also given to verify the energy efficient parameters and their contributions to sustainability as laid down by GRIHA. The study will be instrumental in formulating new concepts for sustainable conservation and green concepts for reviving and maintain traditional construction methods which could eventually give rise to new cultural studio space for the contemporary society.
\end{abstract}

Keywords:Community and cultural progression space, Environmental factors, Koothambalam.

\section{INTRODUCTION}

Traditional Sanskrit theatre is a kind of temple theatre thatis located inside a major temple complex.The temple theatres have long been an inseparable part of Kerala's cultural past. The temple theatres host traditional performing art forms likeKoodiyattom/Kuttiyattam, Chakyar Koothu, Nangiarkoothu, Ottamthullal, etc.The native temple theatres are called as 'Koothambalam'in the local parlance or temple theatre which is aclosed hall surrounded by wooden trellis-work over a half brick wall above the stone basement from the ground level.

Revised Manuscript Received on December 05, 2019.

* Correspondence Author

Vinayakan Ashokan*, Research Scholar, Kalasalingam School of Architecture, Kalasalingam Academy for Research and Education, TamilNadu, India. Email: vinucev@gmail.com

Dr. (Prof) N.Lakshmi Thilagam, Director \& Professor, Kalasalingam School of Architecture, Kalasalingam Academy for Research and Education, TamilNadu, India. Email: hodbarch@klu.ac.in
This built in area revelasan iconic character of Kerala's traditional architecture constructed on a magnificent scale,composed of carpentry skills and embellishments.These heritage structures have used abundant resources in their construction many of which areredundant and in damaged condition. "Heritage springs from human culture. This is part of human life, from which we learn who we are and how we live, and pass our values to the next generation. Though we have received so much from previous generations and civilizations, yet we act irresponsibly and neglect our heritage" [1]. "For many years it was believed that the production of Sanskrit plays had completely died out and that the traditional theatre structures expressly for Sanskrit drama were no longer in existence"[2]. Many studies have highlighted for the existence of renowned Sanskrit theatres in major temples of Kerala which had survived due to the presence of the traditional performing art forms.

The aim of the paper is to verify the sustainable concepts of heritage buildings in Kerala, particularly the Sanskrit theatre, and to validate it through a specific study of a Koothambalam. There are only avery few tools available to assess sustainable concepts of the heritage buildings. Therefore, this research is conducted through the understanding ofthe relevance of community gathering in the society and its environmental attributes leading to sustainable development. TheUnited Nation's $33^{\text {rd }}$ sustainable development goal is to ensure healthy lives and good wellbeing for all age groups in the society. Social gatherings of the community, and its cultural progression activities in the Koothambalamensure a sustainable approach. Discussion on relevant research papers isalso considered for understanding the nature of community and its cultural progression space.These buildings also possess passive design strategies that have been sustained for centuries. Sustainable attributes like- site planning, energy and occupant comforts, sustainable building materials, social aspects, etc. are discussed for verifying sustainable concepts to the heritage buildings.

Heritage buildings do not have a particular format for verifying the sustainable attributes,and hence GRIHA assessment criteria are used for verifying those sustainable factors.Using GRIHA assessment criteria, the application of sustainable concepts in the Koothambalam of Harippad temple is verified. These studies are essential to preserving heritage buildings and for the benefit of healthy wellbeing through community gatherings. Traditionalconstruction techniquesused in these buildings can be adopted for the benefit of the modern society. 


\section{KOOTHAMBALAM AS A COMMUNITY ANDCULTURAL PROGRESSION SPACE}

"The Koothambalam hosts a traditional form of Sanskrit theatre called Koodiyattam, which has been practiced for almost 2,000 years without a break"[3]. "However, the spatial needs of many traditional Indian performance forms are completely different. On the one hand, many of these traditions have a history of performing in the found spaces of everyday social life; temple porticos, fairgrounds and courtyards of large houses. On the other hand are the few remaining traditions like that of Koodiyattam which was recently declared by UNESCO to be a 'masterpiece of the old and intangible heritage of humanity" [4]. This performance structure made a transformation by entering into the temples during the period14th -19 th Century. The performance spaces were different and dynamics for which the spaces were shifted from place to place within the temple premises to host these art forms. Based on the transformation of these spaces, some were performed in open grounds or (Kuthuparambu), Near to the Sanctum (Valiambalam), long dining hall (Uttupura), porticos of temple entrance (Vatilamatam) or elevated platform spaces (Natakashala).

\section{A. Koothambalam:}

'Koothambalam' or the temple theatre is a closed hall surrounded by wooden trellis-work on a half brick wall and is used for staging traditional cultural performing art forms. It was an addition to the development of the temple enclosure during the 14th century (1301 - 1800 AD). Temples were the focal point of the evolution of cultural activities that gradually spread out. A temple layout constitutes five prakaras and the ideal location area for Koothambalam is between the Bahyahara and the Maryada, which is as shown in Fig 1.

\section{B. Significance of the structure:}

Koothambalam encompasses the typical characteristic feature of Kerala architecture, with the main three components: pyramidal roof, superstructure, and the base or Adisthana. The raised roof tapers up to meet the main ridge where the three finials or Kalasam are positioned. The overhanging sloped roof protects the envelope from the harsh sun and rain, providing ambient shades on all four sides. The superstructure consists of a half wall and trelliswood-work to allow the gentle breeze inside the theatre. The base of the structure is usually constructed of stone and is elevated from the ground level to prevent dampness; it has access from all four sides leading to the inner space of the Koothambalam. In Fig. 2, the various spatial arrangements and the shape of Koothambalam are shown. In the past, the front of the stage, raised or flat, was reserved for Brahmins. The rest was used by people, either to sit or stand. Today, thehierarchy of seating is not class or caste specific but on the basis of gender.Fig. 3 shows the arrangement of spaces in longitudinal and transverse directions. "The deity in Kerala temple faces east or west, though in some cases also south, but whatever the direction of deity faces, the Koothambalam is to the right side of it" [5].
Natyashastra, a Sanskrit text highlighting the basic fundamentals of dance, music, and arts, enumeratesthe construction details of a temple theatre. As per the text, there exist some similarities in the design of a Koothambalam depending on its shape and utility aspects.

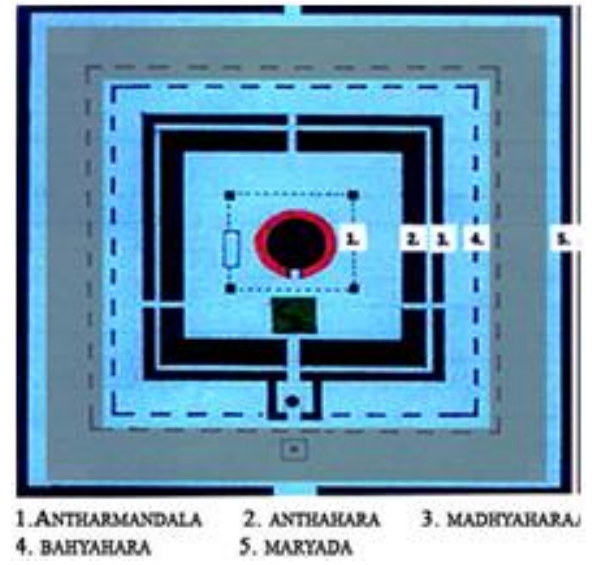

Fig. 1. Shaded portion shows the ideal location of Koothambalam in Panchaprakaras(Various layers of a temple)

Source: Thrikodithanam temple layout.

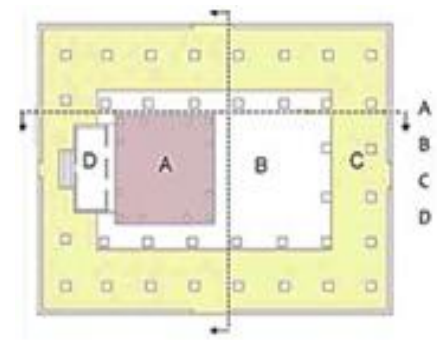

STACE

BRAHMIN LEVEL

PREKSHACAIA

- NEPATHYA / ORESSING ROOM

Fig. 2. Plan of Koothambalam(Various partsof a Koothambalam)

Source: Sreedevi Ajayan, 2009.

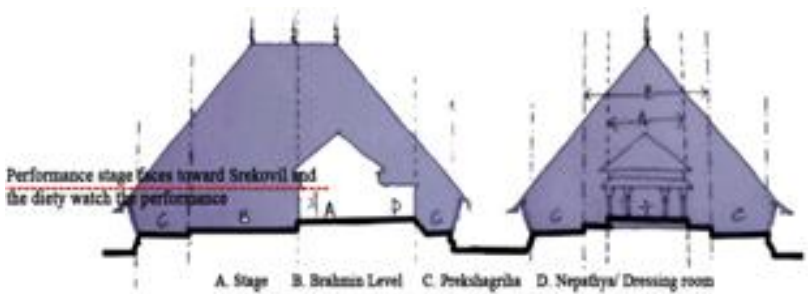

Fig. 3. The spatial configuration of Koothambalam(Various sections of a Koothambalam) Source: Sreedevi Ajayan, 2009 and edited by the author.

\begin{tabular}{|c|c|c|c|}
\hline \multirow[t]{2}{*}{ Shape } & \multicolumn{3}{|c|}{ Sizes } \\
\hline & $\frac{\text { Large }}{\text { (Jyeitha) }}$ & $\frac{\text { Medium }}{\text { (Madiya) }}$ & $\frac{\text { Sinall }}{\text { (Avaro) }}$ \\
\hline & $\mathrm{E}-\mathrm{W} \times \mathrm{N}-\mathrm{S}$ & E-W $\times \mathrm{N}-\mathrm{S}$ & $\mathrm{E}-\mathrm{W} \times \mathrm{N} \cdot \mathrm{S}$ \\
\hline Rectangular & $162^{\prime} \times 81^{\prime}$ & $96^{\prime} \times 48^{\prime}$ & $48^{\prime} \times 24^{\prime}$ \\
\hline (Vilerna) & $106 \mathrm{H} \times 54 \mathrm{H}$ & $64 \mathrm{H} \times 32 \mathrm{H}$ & $32 \mathrm{H} \times 16 \mathrm{H}$ \\
\hline Square & $162^{\prime} \times 162^{\prime}$ & $96^{\circ} \times 96^{\circ}$ & $48^{\circ} \times 48^{\prime}$ \\
\hline (Cotarasra) & $108 \mathrm{H} \times 108 \mathrm{H}$ & $64 \mathrm{H} \times 64 \mathrm{H}$ & $32 \mathrm{H} \times 32 \mathrm{H}$ \\
\hline $\begin{array}{l}\text { Triangular } \\
\text { (Trayasa) }\end{array}$ & \multicolumn{3}{|c|}{ Measurements not given. } \\
\hline
\end{tabular}

Fig. 4. Typology of Sanskrit theatre in Natyashastra(shapes and sizes) 
Source:Taris Mehtra, SanskritPlay Production in Ancient India,vBanarasidas, 1995.

According to Natyashastra, temple theatres are classified into three types: oblong (Vikrsta), square (Caturasra) and triangle (Tryasra). Based on their sizes, they are divided into large (Jyestha), medium (Madhya) and small (Avara). Based on the above types, medium Sanskrit theatres are further subdivided into nine types as shown in Fig.4, of which the measurements for triangular-shaped theatre are undefined. Theatres were a good communication forum to express the cultural reforms between the performer and the audience. As per Natyashastra, "Vikristamadhya (oblong shape and middle-size) type theatre hall is appropriate because it helps the actor to communicate with the audience vocally and physically." [6]

According to someresearch papers, the followingobservations were made about the Koothambalam:

- Theatre spaces in the Indian context can bring in a quality spatial character which could facilitate communication between the performer and audience.

- The play of Sanskrit drama in Koothambalam, the influence of light, sound, visual clarity, etc., plays a vital role in the distraction or concentration between the performer and audience.

- The concept of Natyamandapaproposed by Bharata is widely observed but we can also see changes with regional differences.

- Koothambalamof Kerala is different in its construction and measurements, different from those proposed by Bharata.

- "There is a widespread inequalities exists as Bharata comments, the forward caste is allowed to view these arts by sitting in front of the row and low caste must view the show by staying in outside of the Natyamandapa"[7].

According to Himanshu Brute, "a performance space is a critical variable affecting the culture of theatrical production in any society. Through its impact upon theatrical practice it also has a significant influence upon the broader cultural production of any society" [8].Koothambalam was once a platform for social interaction and gatherings for the community.
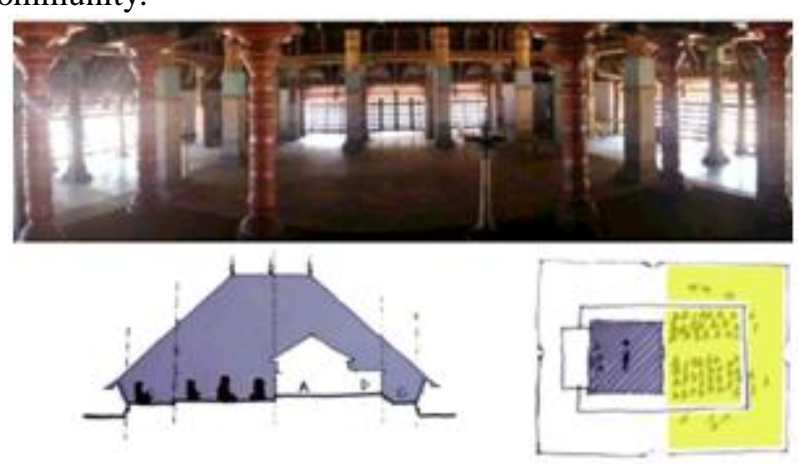

Fig.5. Koothambalam at Vadakunathan temple (Prekshagriha, social gathering and interaction among the community)

Source: Sreedevi Ajayan, 2009 and edited by the author.

In Fig. 5, shows the seating space of Prekshagriha, used as a community gathering platform, learning space for the
Vedas and rehearsal for cultural art forms. Koothambalam is considered so sacred as a temple and is a platform to performvarious plays chosen from the Indian epics. For example, 'Chakyar Koothu' is a narrative performance by lord Ananta (Celestial snake on which the lord Vishnu reclines) reciting the stories of the Mahabharata and the Ramayana. The play is a composition of Sanskrit and Malayalam literature where the Chakyar mimics the characters in the story. Based on the above nature of the play in Koothambalam, it is believed that the God and the Goddess are themselves narrating the play in the 'Rangasira'. The audience considers this as a sacred play for which people show their respects by bowing their head on the floor at the beginning and at the end of the performance.This space was also used as a multidimensional space, serving different activities to create social and cultural integration within the community. As per the sustainable development goals, "target 11.4 highlights the need to strengthen efforts to protect and safeguard the world's culturaland natural heritage" [9]. One of the important aspects of sustainability in heritage building is the social aspect. Koothambalam is a social entity served in bringing security, equity and the sense of place among the community members. "Its existence provides knowledge to present and future generations about the past. Heritage building maintenance could develop skills for local people. For social sustainability, everyone should have a fair access to the buildings, physically or virtually" [10].

\section{ENVIRONMENTAL ASSESSMENT OF KOOTHAMBALAM}

The carbon emissions generated by a heritage building are mainly due to excess electricity usage andby vehicles.The presence of eco-friendly materials and the capacity of the building to adapt to the climate change could result in less energy consumption. The availability of public transport will reduce traffic congestion, contributing to less depletion of natural resources and sir pollution. The compliance codeof the building standards helps to ensure the health and safety of the occupants. "Conservation and sustainability share the same generative basics.

The first and basic concept of sustainability is to use what already exists. Similarly, the basic concept of conservation is to protect what we already have" [11]. Heritage buildings have the advantageof having less consumption of energy and the skills of superior craftsmanship that have definitely contributed to their durability for hundreds of years. The traditional process of building construction in Kerala was primarily guided by historical canons. Craftsmen worked precisely and systematically under the guidance and supervision of the Stapathis. Silparatna (SR) and TantrasamucchayaSilpabhagam (TSB) are two historical texts used for the construction guidelines of the design of Koothambalam. The belowmentioned are the verified sustainable attributesand theiranalysis as per GRIHA criteria: 


\section{A. Site planning}

The Koothambalam is located in the southeast corner of the temple, facing the dietytowards the west and positioned to theright of the east-west parallel axis from the main deity. The four-sided slope roof of the structure helps in easy flow of surface water to the impervious ground surface for good water percolation. The built structure is planned in such a way that minimum proximity is maintained for proper access from the inside or outside wall of the temple (Fig.6).A substantial amount of low energy consumptioncan be achieved by adapting the passive design methods.

"A sustainable site plan has the least environmental impact. The simple act of properly orienting a building can create energy savings of up to $25 \%$ "[12]. Other implementations at site level are:

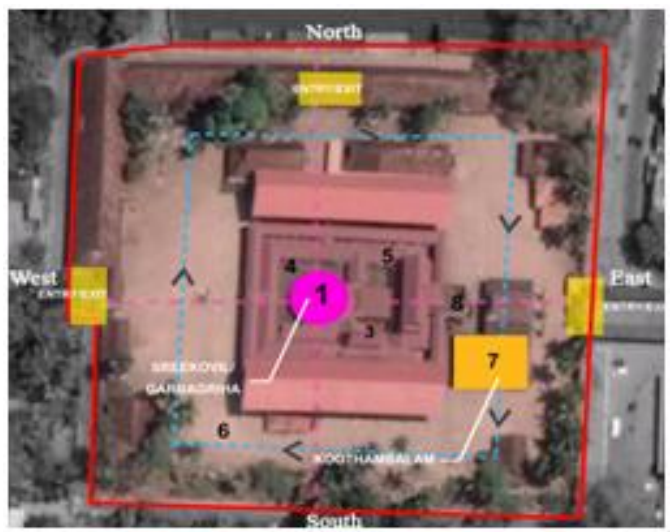

Fig. 6. Site layout of Subramanya temple, Haripad (Site planning)

Source: Google Earth image and edited by the Author.

- Passive design strategies:

The amount of heat dissipates due to maximumopenness seen onboth sides of the built form (Fig. 7). The high structure of Koothambalam dissipates heat through the opening at the 'Mukhappu'.Maximum passive design strategies in terms of shading, orientation for ambient lighting adequate wind movement, and proper structure and visibility, etc. are incorporated to achieve maximum human comfort for the performer as well as the audience.

\section{- Orientation:}

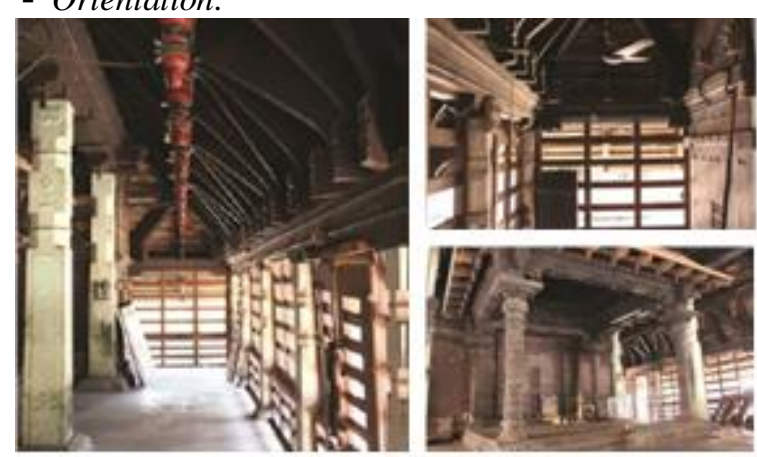

Fig.7. Maximum light from both the sides of Source: Photographs by Ar. Gopika Jayasree.

The extendedroof protects the envelope from direct solar radiation and reducesheat gain in the internal space for audience. The open area can be seen on bothsides of the built up area (Fig. 7). Due to the low roof profile, height Koothambalam(Ventilation around the passage)

from the ground to the eaves and horizontal wooden trellis work, a good amount of daylighting is received and less heat flows into the internal spaces. According to Vijaya lekshmi, "the heat loads reduce by $50 \%$ when only walls are shaded and around $80 \%$ when the roof also is shaded" [13]. Traditional buildings in Kerala have wooden trellis wall for covering the internal space and have steep roof to protect area from the harsh external climate.

\section{- Building massing.}

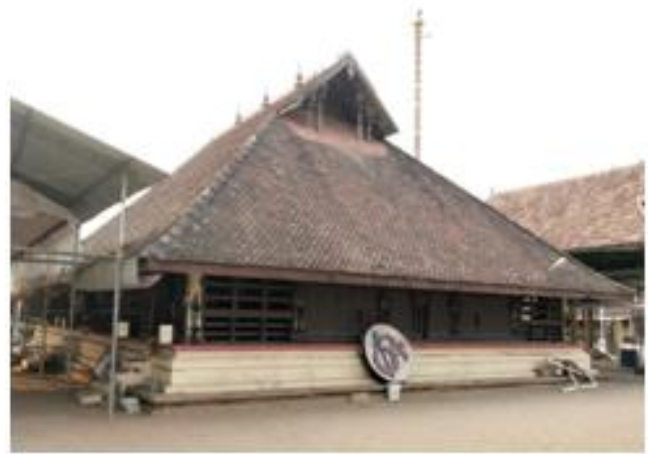

Fig.8. Koothambalam at Subramanya temple, Haripad. Source: Author

The iconic element in the building design is the roof structure (as shown in Fig.8). Thestructure is designed according to human scale proportion and its emphasis on the roofing structure as a visual character of the built form. Due to the low profile of the roof and buffer space in the internalperipheral area, the audience area receives passive cooling. The roofing at the top protrudes out to the trellis board which is fixed to Mukhappu.

- Spatial Conditioning:

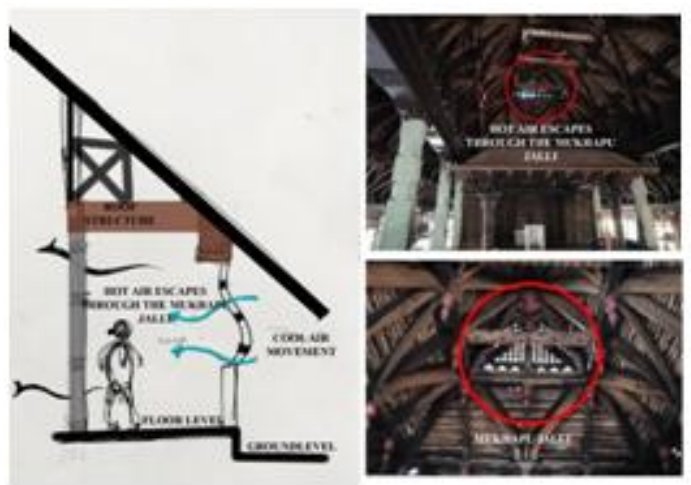

Fig. 9. Schematic section shows the comfort factor (Spatial conditioning)

Source: Photograph edited by the author.

The building is naturally conditioned and all four wall sides of the structure are surrounded byhalf wall and wooden trellis work.The cool air entering the building envelope from all the sides cools down the internal spaces naturally and the dissipated heat loads escape through the 'jalli'works at the Mukhappuin the roof.

\section{B. Mitigating Urban Heat Island (UHI)effect}

Protection and preservation of natural resources onsite vegetation and effective ground cover whichallow stormwater management

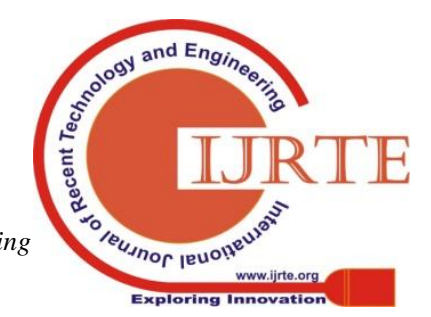


and percolation of rainwater are the hallmarks of traditional Koothambalams.Surface materials that cause the effect of UHI aresparinglyused in making the concrete surface areas on the ground providing moregreen vegetation that gives shade and reduces the ambient temperature more than $50 \%$ of building to sky factor allowing surplus wind movement. The clay roofing materials haveless heat dissipating andingress. "The indoor climate can have a significant effect on an occupant's sense of well-being and clay perform very well in this respect.The high thermal mass of clay building materials means that they are ideal for use in solid, cavity and externally insulated walls, reducing fluctuations in temperature by absorbing thermal energy when the surroundings are higher in temperature than the mass, and giving thermal energy back when the surroundings are cooler.Clay bricks and blocks can therefore be seen as the perfect material to provide a healthy indoor air quality"[14]. Hence the occurrence of heat island is very unlikely to happen due to the use of natural materials as surface materials in the construction ofthe roof and also due togood amount of vegetation that can resist the harsh solar radiation.Impervious surface also helps the refill of groundwater recharging and cools down the outdoor temperature.

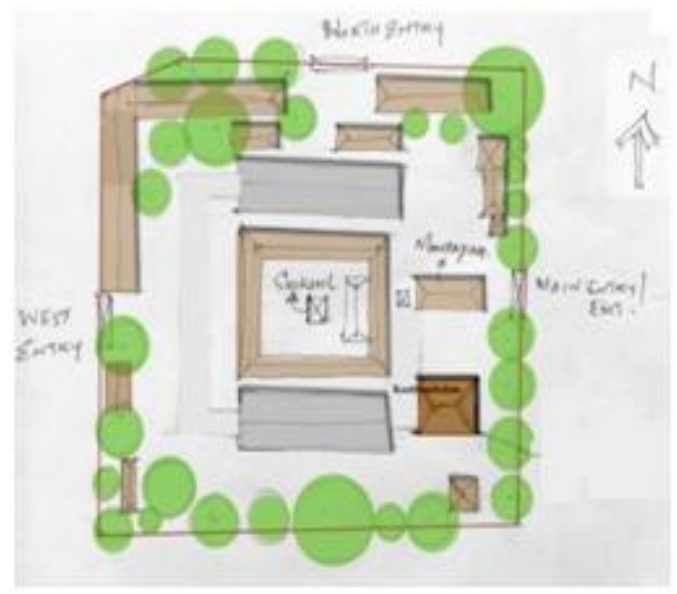

Fig.10. Layout of Subramanya temple, Haripad(Ground cover, surface materials and vegetation around the complex)

Source: Author

\section{Enveloping thermal performance and visual comfort:}

The maximum open area in the building envelope and the use of low heat-dissipating materials, provide a natural comfort in the internal spaces. The building, while perceived externally and internally,renders a visual feast. "Control of the indoor environment is always an important aspect of traditional architecture. Vernacular and traditional systems of construction are ecologically responsive and energy efficient" [15].

Theinfluence of ambient light, sound and visual comforts, there is a contact between the performer and the audience. The relationship of the measurement between the Rangasira and the Prekshagrihacould influence distraction or concentration depending on the different shapes and sizes of the temple theatres as mentioned in Natyashastra.

\section{Sustainable building materials:}

Many local materials are used for the construction of these temple theatres. Materials like lime or surkhi mortarwere used for plastering and as a binding agent for the walls. Wood was extensively used for the wall louvers;roof structures andintricate works for the ceiling of the Rangasira. Natural painting substances like a mixture of egg white, charcoal powder and coloring pigments such as berries were used for ornamental components like column, flooring, etc.

All insulationmaterials are natural and free from chlorofluorocarbonsand hydro chlorofluorocarbon. The use of locally available materials and construction techniques of these buildings show the economic factor and third principle of sustainability. The economic viability and cost effectivenessof Koothambalamare to be studiedfor their application in the design and construction.

\section{E. Social aspects:}

Accessibility to the temple theatre through public transit infrastructure and basic necessities are available within $500 \mathrm{~m}$ around the temple complex as shown in Fig 11.Five basic services are available within the immediate vicinity.

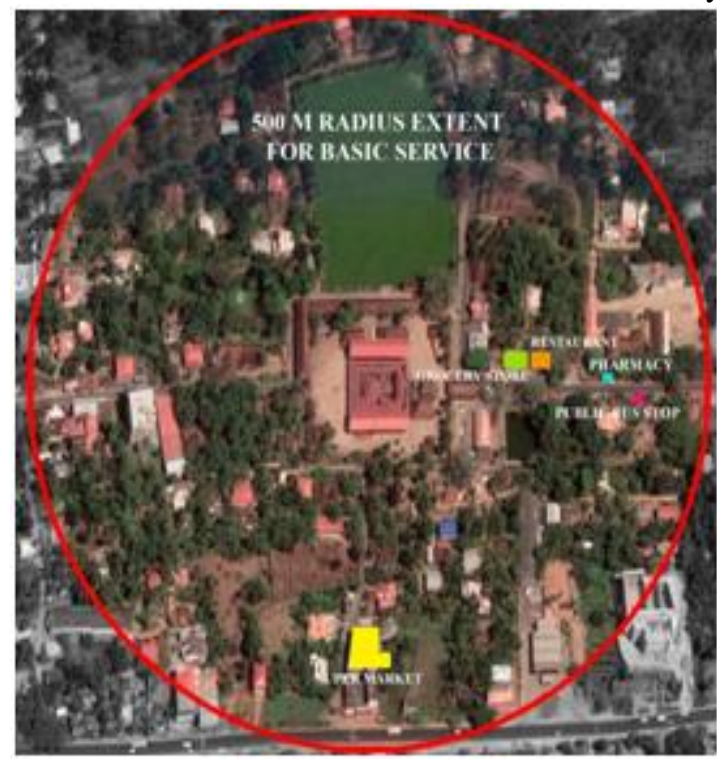

Fig.11. $500 \mathrm{~m}$ radius proximity to transport and basic servicesaround Harippad temple complex(Socialaspects).

Source: Google Earth image and edited by the author.

Based on the GRIHA assessment criteria, Koothambalam of Harippad Sree Subramanya temple is built on the requirements of sustainability. The temple theatre is a living example of the environmental principles for sustainability,as stipulated by GRIHA. This substantiates the fact that the Koothambalam haslasted for ages in terms of the ecological footprint, giving way to minimal negative impact on the environment. According to sustainable development goals, Target 12.2, "By 2030, achieve the sustainable management and efficient use of natural resourcesand Target 12.5 , By 2030, substantially reduce the waste generation through prevention, reduction, recycling and reuse" [16]. 
Traditional architectural practices were followed in a sustainablemannerand, we should make sure we conserve these heritage structures from neglect through an approach for sustainable conservationbased on the ecosystem. According to the sustainable development goals, preservation and prevention are the best suitableconservation strategies for achieving sustainabilitywhich needs only a minimumenergy. The structures can be retained to their original state through minimal intervention, but when kept unused the building tends to get deteriorated, causing loss of many resources and increasing energy consumption.

\section{CONCLUSION}

Based on the discussion of the social, cultural and environmental factors in sustainability, Koothambalam of Harippad temple substantiates the essence of sustainable attributes. The built up heritage adheres to the concept and principles of sustainabilitywhichaddresses the various aspects of environment, economic,social and cultural aspectsof sustainable development. Preserving these entitieswill result in the reduction of energy consumption and will maintain the architectural integrity of the structure.The new generation innovations togetherwith theknowledge of traditional construction methods and their implications could auger well for the environment. These heritage buildings are to be conserved, not only for the value of sustainability but also for reviving the diminishing cultural values of the art forms fromthe temple theatres ofKerala.In order to maintainsustainable conservation, the application of architecture will have relevance in the adaptive reuse, performance and practice centers, etc. and in maintaining social, environmental and economic values of the society which will enhancethe modernuser's comfort and energy-efficient standards. Therefore, Koothambalam with its traditional architecture of Kerala is a living example of Sustainable building design and it needs to be further studied for its application in asimilar context.

\section{REFERENCES}

1. Reena Thakur Patra, "Vaastu in perspective of technology",UK:International Research and Education Journal (IERJ), Vol.3, Issue-5, E-ISSN No : 2454-9916, 2018, PP 776.

2. C.R Jones, "Source material for the construction of the Natyamandapa in the Silparatna and the Tantrasamuccaya Silpa Bhagam", US:Journal of the American Oriental Society (JAOS), 1973, PP 286.

3. Himanshu Brute, "Performers as Placemakers- Uncomplicated drama spaces", London:Theatre Engineering and Architecture Conference 2006, PA 4-2.

4. Ibid., PA 4-3.

5. Dr. Harimohan Pillai. (2004), Ritualistic articulation Performance spaces[blog], Available:http://www.archiestudio.in/demystifying_m_arch/ritualistic_articulation___performance_spaces

6. M M Ghosh(translator), The Natyasastra ascribed to Bharata-Muni, Asiatic Society of Bengal, Calcutta, vol.1, op. cit., pp.28-29(chapter .2 Hymn 75-80), 1951.

7. Sajeesh CS, "The concept of theatre in Naatyashaastra and classical art forms of Kerala", New Delhi:International Journal of Sanskrit Research, 2016, PP. 78-79.

8. Himanshu Brute, "Performers as Placemakers- Uncomplicated drama spaces", London: Theatre Engineering and Architecture Conference 2006, PA 4-2.

9. United cities and local government (UCGL), "Culture in the sustainabledevelopment goal: a guide for local action", SPAIN:UGC committee culture 21, 2018, PP 3.

10. Ervi Luisman, Daniel C.W.HO, Janet X. GE, "Indicators for heritage buildings sustainability",Prague:Central Europe towards sustainable building,Decision support tools and assessment methods, International Conference, 2013, PP 3.

11. Ahmed M. R. Khalil, Naglaa Y. Hammouda, Khaled F. El-Deeb, "Implementing Sustainability in Retrofitting Heritage Buildings. Case Study: Villa Antoniadis, Alexandria, Egypt", Heritage 2018, Vol. 1, PP 58.

12. Bob Faulhaber. (2011, July 06, Wednesday), Sustainable site planning basics[blog], Available: http://www.buildipedia.com/aec-pros/urbanplanning/sustainable-site-planning-basics

13. Tiles \& Bricks Europe (TBE). (2015), Sustainability- 12 reasons why clay construction products are socially, environmentally and economically sustainable [blog], Available:http://www.tilesbricks.eu/sustainability

14. Vijaya laksmi Akella, "Thermal performance of traditional and modern buildings in Kerala, South India", Tokyo:World sustainable building conference, September 2005, PP 2111.

15. Kavitha S, Praveen D Dethan, Hrithuparna S H, "Traditional Architecture of Kerala and Sustainability", Trichy, Tamilnadu:International Research Journal of Engineering and Technology (IRJET), 2018, PP. 1930.

16. United nations sustainable development goals(SDGS), "Transforming our world: The 2030 agenda for sustainable development", SPAIN:UGC committee culture 21, A/RES/70/1, 2019, PP 24.

\section{GLOSSARY}

1. Koodiyattom/Kuttiyattam: A Combined acting or dramain Sanskrit theatres with the elements of Koothu.

2. ChakiarKoothu:A solo performance by Anantha (thousand-headed serpent), narrates stories with an outfit of black moustache, smeared in sandal paste and red dots on body.

3. Nangiarkoothu: An allied art of Koodiyattam, performed by the women of the Ambalavasi community called Nangyaramma. The hand gestures, facial expressions and body movements performed for the story of Lord Krishna are accompainedwith the rhythm of the Mizhavu instrument.

4. Ottamthullal:A solo dance and poetic form performance form andaccompained by a mridangam (a barrel-shaped double-headed drum) or an idakka (drum and cymbal).

5. Kathakali: It is an Indian classical dance form that is distinguished by the elaborately colorful make-up, costumes, and facemasks worn by the male actors.

6. Nallambalam: The circumambulation of the inner wall precinct of a Kerala temple.

7. Chuttambalam: The circumambulation of the outerwallprecinctof a Kerala temple.

8. Bhayahara:This is the fourth enclosure and forms a pathway for the procession within the temple complex.

9. Maryaada:Theis the fifth and last wall of the temple complex inthe panchaprakaras..

10. Prekshagagriha:Seating space or audience area inside a Koothambalam.

11. Stapathi:The chief carpenter who advises and gives training for other workers.

12. Rangasira: The elevated platform or stage of a Koothambalam.

13. Mukhappu:It is an aesthetic character positioned at the head of a sloping roof structure.

\section{AUTHORS PROFILE}

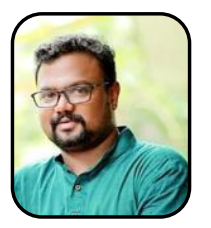

Ar. Vinayakan Ashokanis pursuing a Ph.D. in Architecture from the School of Architecture, Kalasalingam Academy for Research and Education, TamilNadu, India. He has acquired his B-arch. degree from Sathyabama University, Chennai and M-arch. Degree from MEASI Academy of Architecture, Affiliated to Anna University, Chennai. $\mathrm{He}$ is a Registered Architect withCouncil of Architecture, India and an associate member of the Indian Institute of Architecture. He has professional exposure in the Middle East and India, working on significant architectural and government projects. Currently working as the Head of the Department at NRM School of Architecture (Affiliated to CUSAT University), Kollam, Kerala. 
Dr. N. Lakshmi Thilagam is an Architect and Urban Designer and holds a $\mathrm{PhD}$ from the Indian Institute of Technology, Kharagpur, India. Her research interests are traditional urbanism, space syntax application for historic cities, heritage and urban conservation. She is currently conductingresearch to analyze the principles of sustainability exhibited in the traditional urban patterns of the historic cities of Tamil Nadu. As a passionate academician who has been teaching for the last 2 decades she also writes on the subjectof Architectural education. 